\title{
O MÉTODO DE MICHEL FOUCAULT E A LINGUAGEM DA PSICANÁLISE
}

\author{
EL MÉTODO DE MICHEL FOUCAULT Y EL \\ LENGUAJE DEL PSICOANÁLISIS \\ MICHEL FOUCAULT'S METHOD AND THE \\ PSTCHOANALTSIS' LANGUAGE
}

\author{
Estevan Ketzer ${ }^{1}$ \\ ${ }^{1}$ Pontifícia Universidade Católica do Rio Grande do Sul, Porto Alegre/RS, Brasil
}

\begin{abstract}
RESUMO: O filósofo francês Michel Foucault discute a psicanálise através de seu método arqueológico da constituição dos saberes na modernidade. A análise foucaultiana revela uma reestruturação crítica dos saberes, que parte do estudo das estruturas sociais, atribuindo a estas um caráter arbitrário e cerceador. Neste ponto, o autor se detém no modo como a psicanálise freudiana pensa a dinâmica das relações sociais ao construir uma linguagem. Contudo, Foucault encontra nesta proposta um domínio da ideia de prazer, a partir da sexualidade, atribuindo saber à figura do psicanalista. Isto entra em contradição com a prática dos psicanalistas imbuídos do desejo de produção de saúde. A concepção tardia de Foucault, acerca da vida como obra de arte, acaba sendo um lugar preferencial para a ética da psicanálise e das formas de experimentação da realidade que não se reduzem ao social somente pela opressão de um saber psicológico detentor de poder dessimétrico.

PALAVRAS-CHAVE: Foucault; Sexualidade; Psicanálise; Poder.
\end{abstract}

RESUMEN: El filósofo francés Michel Foucault analiza el psicoanálisis a través de su método arqueológico de la constitución de los saberes en la modernidad. El análisis de Foucault revela una reestructuración crítica de los saberes, que parte del estudio de las estructuras sociales, atribuyéndoles un carácter arbitrario y restrictivo. En este punto, el autor se detiene en la forma en que el psicoanálisis freudiano piensa la dinámica de las relaciones sociales al construir un lenguaje. Sin embargo, Foucault encuentra en esta propuesta un dominio de la idea del placer, basada en la sexualidad, atribuyendo el saber a la figura del psicoanalista. Esto contradice la práctica de los psicoanalistas imbuidos del deseo de producir salud. La concepción tardía de Foucault sobre la vida como una obra de arte termina siendo un lugar preferencial para la ética del psicoanálisis y las formas de experimentación de la realidad que no se reducen a lo social solo por la opresión de un saber psicológico que tiene el poder asimétrico.

PALABRAS CLAVE: Foucault; Sexualidad; Psicoanálisis; Poder.

ABSTRACT: The article brings the French philosopher Michel Foucault's discussion about psychoanalysis, which he conducts through his archaeological method on the constitution of modernity's knowledge. Foucault's analysis reveals a critical restructuring of knowledge, departing from the study of social structures and attributing to them an arbitrary and restrictive character. At this point, the author is especially concerned with the way in which Freudian psychoanalysis thinks the dynamics of social relations when constructing a language. However, in this proposal of language, Foucault finds a domain over the idea of pleasure from sexuality, which places knowledge in the psychoanalyst's character. This is found in deep contradiction with the practice of psychoanalysts who are imbued with the desire for promoting health. Foucault's late conception of life as a work of art ends up being a preferential place for psychoanalysis' ethics and the ways of experiencing reality that are not reduced to the social only by the oppression of a psychological knowledge that detains dissymmetric power.

KEYWORDS: Foucault; sexuality; psychoanalysis; power. 
"A análise freudiana nunca retoma senão um dos sentidos possíveis pelos atalhos da adivinhação ou pelos longos caminhos da probabilidade: o próprio ato expressivo jamais é reconstituído em sua necessidade"

Michel Foucault na Introdução ao livro Sonho e Existência, de Ludwig Binswanger $(1954 / 2013)$

\section{Introdução}

Por que o método? Sem um método, ainda que possamos duvidar dos achados de inúmeras maneiras, perdemos certamente a minúcia que lentamente foi depositado sobre toda a gama de saberes ali colocados. Por vezes, voltar ao passado é necessário para rever o que foi pretendido e esbater com o estabelecido. Não por nada o conhecimento científico se consolidou em uma determinada prática que, com o passar do tempo, foi institucionalizada. Não é menos tortuoso que o termo "verdade científica" tenha passado inicialmente pelas ciências naturais, uma vez que seu método é extremamente rigoroso, determinando a repartição do todo em partes (o termo "análise" surge como método). Mas se analisarmos cada parte de maneira tão cirúrgica, veremos o objeto ou uma parte desintegrada de seu todo? E, talvez, mais estarrecedor do que este fato: acabamos por perder inclusive a possibilidade de sermos contemplados "pelo" objeto. Esta questão não é posta pelo frio objetivismo das ciências naturais. Enquanto questão ela não pode ser assim colocada, pois inviabiliza a ciência positivista como um todo, pois a perda da objetividade e a valorização da positividade garantem um olhar isento, neutro, sobre o objeto que será decupado.

Para Foucault (1957/1999), a questão é mais radical quando nem mesmo a apreensão de um sentido se mostra suficiente para tomar o lugar que a ciência natural havia se apropriado. Fazer isso é justamente limitar a ciência psicológica, de perspectiva naturalista por base, e todo o seu universo histórico até o ponto de vista irremediavelmente metafísico. Diferentemente disso, o método da psicanálise traz o passado ao presente. $\mathrm{O}$ presente vivencia um sentido pleno, mesmo que insensato, inconsciente, interrompido. "A consciência e o inconsciente não são tanto dois mundos justapostos; são, antes, duas modalidades de uma mesma significação" (Foucault, p. 130). Foucault nitidamente mostra uma dialética indecomponível, uma vez que já está estabelecida na dinâmica dos conflitos entre consciente e inconsciente. Mesmo algo não percebido foi vivido e experimentado de determinada forma. É por ser um jogo inescapável que o conflito possui um significado em seu próprio embate dual.

Foucault não queria que as investigações em psicologia terminassem com o advento da psicanálise ao embater-se com o significado inconsciente. Pelo contrário, era clara a vontade de Foucault em adentrar-se para uma outra dinâmica de conflitos deixados de lado pela psicanálise. Para nós, esses conflitos devem ser aqui investigados com o objetivo de trazer mais questões para a psicanálise, não acerca de seu passado, mas acerca de seu futuro como instituição. 


\section{O método de Foucault}

Há um problema muito grave quando se fala da psicanálise apenas em seu sentido teórico: é possível falar tudo dela sem jamais ter vivenciado nenhum dos seus achados. Por exemplo: uma fala torna-se leviana, ainda que interessada no que está por trás do método psicanalítico, e pode negar a existência de um inconsciente por nunca ter vivenciado sua expressão. Esta fala é tida como dogmática por não ter evidência clara de que o inconsciente não existe. Por esta simples razão, somos remetidos a falar de uma "disciplina da suspeita”, como Paul Ricoeur (1978) bem conceitua. A psicanálise é cheia de sujeitos suspeitos, da suspeita do princípio de que a modernidade deve convergir para um único e consolidado lado. "Uma reflexão sobre os limites da interpretação freudiana permanece em suspenso, como permanece em suspenso a significação profunda dessa grande subversão da consciência de si inaugurada por Marx, Nietzsche e Freud” (Ricoeur, 1978, p. 136).

Foucault reconhece na pesquisa em ciências humanas na alta modernidade a suspeita vinda a partir de suas famigeradas "técnicas de interpretação." (Foucault, 1982/2005, p. 47) Tais técnicas para interpretar o mundo moderno, tanto em Freud, quanto em Nietzsche e Marx, passam uma por uma negação da linguagem tal como esperamos que ela seja, indiferentemente de nossos encontros com a realidade em sua constituição. Não era esperado da linguagem, pelo menos pelo ideal moderno, que ela refletisse seu próprio olhar. Uma reflexão aprofundada sobre suas condições e as implicações instituídas para parecem como progresso do conhecimento científico. Contudo, a linguagem também representa a nossa fala: é narcisista e autoimune, incrédula, responde mal as críticas que lhe são feitas, enxergando-as como ataques.

Freud desencadeia um processo de questionamento ininterrupto e impreterível. Mais ainda, ele mostra o quanto a consciência é derivada de um profundo inconsciente. $\mathrm{O}$ intérprete joga entre as diferentes camadas do conhecimento e com isso desenvolve uma nova e consubstanciada visão sobre o que terá de impreterivelmente interrogar. "Inclusive Freud, não interpreta símbolos, mas interpretações.” (Foucault, 1982/2005, p. 58) O sintoma é uma interpretação antes de ser signo, isso já diz muito sobre o paciente e do que ainda não significa nada enquanto totalidade. É num determinado estágio do tempo moderno que a interpretação precisará se tornar vigorosa o bastante para adentrar na lama dos processos subjetivos, estes carentes não de significação ou clareza, mas de novos processos, ainda a serem inventados. "A vida da interpretação, pelo contrário, é o crer que não há mais do que interpretações.” (p. 62) Neste sentido fica claro para o filósofo francês que a semiologia é perigosa para uma hermenêutica, uma vez que seus postulados sobre a formação da linguagem adquirem no símbolo uma força desproporcional de significação, em detrimento da interpretação e seu jogo que é, por natureza, mais complexo do que o binarismo meramente linguístico (significado e significante).

Não esperamos com isso encontrar total coerência no pensamento de Foucault ou pureza teórica. A contaminação é um princípio a ser usado neste jogo, contaminar-se justamente com aquilo que não é possível santificar-se e que se está comprometido. Isto significa dizer que as relações existem mesmo que o consciente decida constituir outro jogo com outras peças. O que está por fora da consciência, mas também o que está por fora do inconsciente, a forma na qual os discursos se dirigem e formam laços sociais duráveis. Eis a aparência de natureza que as coisas se tornam aos sentidos. A tentativa insistente em dar funcionalidade a estruturas que deveriam evoluir, mas acabam por perderem sua vitalidade de emancipação. Elas cederam a um jogo político sem o saberem. 
Como não enxergar este desafio a ser enfrentado por toda a sociedade? Isto implica o intelectual a algo muito mais complexo, exige dele um posicionamento político em defesa daquilo que está em jogo na cadeia das ideias. Ainda que ele não tenha como mudar o mundo, é dever dele pensar, e pensar não é algo simples de se fazer. Os trabalhos de Foucault possuem este enfoque: História da Loucura (1961/2004); O Nascimento da Clínica (1977); As palavras e as coisas (1966/2007); Arqueologia do saber (1969/1995); A ordem do discurso (1970/2006). Em todos eles, o projeto de Foucault se mostra tal como um adentramento nas questões postas pela crítica ao ideal do pensamento moderno, o encontro com a verdade da humanidade, levando este ideal para outras vias que acabaram por trazer um benefício muito específico para determinadas classes. No caso de História da loucura, sua tese de 1961, é acerca da disciplina médica que recaem suas indagações. O diagnóstico se apresenta de modo contundente: todo o saber exerce um poder. Não poderia ser diferente, pois a ciência começa a ditar aos poucos como devem proceder decisões de cunho judicial, entranhando-se na política de uma forma ingênua, inclusive para que haja a garantia do funcionamento de determinadas instituições regulatórias da vida em sociedade.

Na conversa entre Foucault e Deleuze fica muito evidente que há dependências criadas nas relações de poder: "Quem fala e age? Sempre uma multiplicidade, mesmo que seja na pessoa que fala ou age. Nós somos pequenos grupos. Não existe mais representação, só existe ação" (Foucault, 1979/2013, p. 130). O intelectual não se verá respaldado jamais em uma teoria, mas fará da teoria uma prática sempre a ser interrogada, também para que esta não vire uma instituição reguladora de todas as atividades. Neste período de seu pensamento, vemos o quanto o poder irradiado, que serve para infantilizar certas práticas sociais. O poder está em detrimento do povo, não em seu benefício. Assim, uma instituição, seja ela qual for, implanta a voz do instituído, a voz de comando sobre os corpos que lutam já enganchados sobre as articulações e as expectativas sociais. Passa a ser um dever do intelectual a luta contra os poderes totalitários que geram essa violência institucional, ainda que não tenhamos qualquer princípio fundacional que possamos estar atrelados. É necessária uma luta cotidiana ter de restituir a justiça diante da máquina destruidora do mundo moderno; reinventar os lugares comuns ou simples achados que simplesmente podemos produzir para termos uma garantia de felicidade.

Com o tempo, Foucault modificou seu questionamento acerca das instituições e na maneira com a qual elas foram se solidificando. Antes delas, o poder já possui irradiações não esperadas nos discursos proclamados. "O poder está em toda a parte; não porque englobe tudo e sim porque provém de todos os lugares” (Foucault, 1976/2003, p. 89). Esta obra coloca a contribuição de Foucault para o exame dos dispositivos ${ }^{1}$ de poder para além de práticas institucionais formalizadas por um corpo de conhecimentos rígidos. As formas de poder não se apresentam somente por um ordenamento, mas justamente por haver uma desordem no sistema, dando a impressão de, além de possuírem um espaço físico determinado, serem naturalmente articuladas no transcurso do tempo. Para o pensador francês, este fato é o indicativo "tabus", anúncio de discursos que elencam dificuldades cognoscentes, tais como o silenciamento e os determinados segredos com finalidades para o controle social. É neste espaço que o corpo se torna jogo de forças, a histerização da mulher e a predileção pelas práticas heterossexuais, tais como aparecem em História da sexualidade, vol. 1 (Foucault, 1976/2003). Estas são todas escolhas a serem levadas em consideração, pois acabam servindo para uma certa prescrição da atividade da sexualidade com uma finalidade à normatização. 
Teria a modernidade se normatizado? E mais estarrecedor pode ser para nós que justamente alguns dos dispositivos que nos possibilitariam questionar a o monopólio das normas teriam ao final encontrado um lugar de aparente crítica, mas terminado num esboço incompleto desta análise, ainda a ser feito. Será este o horizonte da crítica de Foucault, a alguns dispositivos que ele encontra na psicanálise, o foco de nossa discussão a partir de agora.

\section{A crítica de Foucault à psicanálise}

O discurso de Foucault coloca outros elementos que estão fora do vocabulário corrente da psicanálise. Suas considerações críticas irão envolver não apenas a interpretação psicanalítica, mas sua operação enquanto política institucional, política dos sonhos e dos desejos da modernidade. Como a instituição da psicanálise foi capaz de operar dissociada da sociedade? Ou ao invés de "como" a questão deveria ser "por quê"? Estabelece-se uma teoria e uma prática, recriando o que anteriormente a sensibilidade não percebera, mas, ao fazer isso, deixa de fora a possibilidade da palavra não se coadunar a um signo semântico, is to é, encerrado em sua relação determinada com a expectativa do campo teórico, mas antes com uma implicação do escutar através das demandas sociais. Este paralelo interpretativo proposto por Foucault tem em mira como a psicanálise acaba permanecendo restrita a determinados processos de entendimento que desembocam num signo opressor com uma nefasta finalidade coercitiva.

Esta crítica já está no primeiro trabalho de Foucault, uma extensa introdução ao livro Le rêve et l'existence, do psicanalista suíço Ludwig Binswanger, publicado em $1954^{2}$. Foucault propõe que a imagem criada durante o sonho possa ganhar vida própria para eximir-se de uma análise semântica redutora:

A distância entre a significação e a imagem não é jamais preenchida pela interpretação analítica a não ser por um excedente de sentido; a imagem em sua plenitude é determinada por sobredeterminação. A dimensão propriamente imaginária da expressão significativa é inteiramente omitida. (Foucault, 1954/1999, p. 70)

Para tanto, nos é necessário pensar sobre o que seja o imaginário, uma vez que talvez estejamos pensando no imaginário restrito à interpretação e não mais a uma fala livre. Justamente é este o problema de se entender a conflitiva edípica da psicossexualidade de uma maneira artificial, buscando uma solução de fora, por via de uma linguagem que não seja a do sonhador. Isto traz sérios danos à interpretação e à relação com o paciente, pessoa exterior ao pensamento do analista. Este problema traz um descompasso com os primeiros estudos sociológicos e filosóficos, uma vez que uma competição conceitual se instaura no monopólio do saber acadêmico francês. O conceito de inconsciente proposto por Freud não parece suficientemente lógico para a linguagem da filosofia ${ }^{3}$. A dimensão entre imaginário e significação tem de gerar um excedente semântico, um excesso impensado, vivido pelo paciente no momento da interpretação. O filósofo também critica este excesso, uma vez que o imaginário se submete a esta escolha semântica unidimensional. 
Em sua extensa introdução ao trabalho de Binswanger, Foucault enxerga a psicanálise intervindo no sonho somente pela palavra, identificando o signo com um suposto sentido a ser decifrado, fazendo da palavra um "atalho". Para Foucault, Freud é o resultado de uma metafísica agonizante em busca de um princípio único e primitivo, uma lei de causalidade psíquica, cuja sexualidade infantil está na base de sua sustentação teórica. A busca por uma imagem mais plástica e material ao invés de atribuir força à palavra acaba por revelar algo reduzido a ideia de um suposto sujeito. "Portanto, no domínio da exploração da psicanálise, não foi encontrada a unidade entre uma psicologia da Imago, que marca o campo da presença, e uma psicologia do sentido que define o campo das virtualidades da linguagem. A psicanálise jamais conseguiu fazer falar as imagens." (Foucault, 1954/1999, p. 73) Porque justamente o que se expressa nas imagens é algo do paciente que não consegue falar e ganha forma pela emulsão do excesso vivido (catarsis). Este fator Foucault deixa de fora de seu conjunto. Por quê?

O verbal não alcança sua significação ideal, uma vez que o ideal é justamente o motivo que mantém a imagem somente uma aparência sem vivência. Será que esta vivência trazida à luz não é uma pré-determinação sem contestação? Isto reduz a dialética a uma submissão e, posteriormente, a uma assimilação que irromperia em um bom comportamento. Foucault de modo algum pode aceitar esta submissão, pois restringe a multiplicidade de elementos para o privilégio de um sentido. Para ele a contradição entre "sintoma" e "sentido" é um obstáculo a ser ultrapassado:

A psicanálise (...) sempre confundiu as duas estruturas; ela define o sentido através do cotejo dos signos objetivos e coincidências do deciframento. Por este fato, entre o sentido e a expressão, a análise freudiana só podia reconhecer um laço artificial: a natureza alucinatória da satisfação do desejo. Em sentido oposto, a fenomenologia permite reaprender a significação no contexto do ato expressivo que a funda: nesta medida, uma descrição fenomenológica sabe tornar manifesta a presença do sentido em um conteúdo imaginário. (Foucault, 1954/1999, p. 78)

O filósofo francês tem em mira que o sonho é antes de uma tentativa de tornar a psicologia palpável, ou mesmo analisável pela psicanálise. A expressão supera a intenção inconsciente do sonhador. Como apreender sua expressão sem o desrespeito que muitas vezes a palavra apressada do psicanalista impõe à pessoa do paciente? $\mathrm{O}$ desejo não pode avançar por um domínio que não é a propriedade da imagem. O sonho tem um lugar na “experiência imaginária” (Foucault, 1954/1999, p. 80) humana. É um complemento à teoria do conhecimento e por esta razão não pode haver a primazia de "um" sentido privilegiado.

Portanto, o objeto do sonho é imaginário e livre para ser imaginado. Há algo de transcendente enquanto objeto, sem que recaia em um inconsciente coletivo, tal como pensado por Jung. Não é do escopo deste artigo nos determos sobre estas questões, uma vez que elas chegam até a psicanálise como apontamentos ulteriores derivados do desenvolvimento do trabalho dos psicanalistas ao redor do mundo. Foucault parece estar olhando para os desenvolvimentos ulteriores da psicanálise sem conhecer seus interlocutores da escola inglesa, por exemplo. É no debate com a obra freudiana que encontramos novos caminhos para problemas muito antigos, inclusive problemas que revelam uma dificuldade de interlocução da psicanálise com os conhecimentos ao seu redor. O próprio sonho, além de gerar um compromisso com o sonhador, também gera um ponto fechado, o umbigo do sonho, como referiu Freud em A interpretação dos sonhos (1900/1975). 
Observamos o quanto a diferença continua profunda entre o "imaginário", o que o sonhador pensa, e a "imagem" propriamente dita:

Não obstante o gênio de Freud poderia dar testemunho disso, já que ele percebeu muito bem que o sentido do sonho não era para ser buscado no nível do conteúdo das imagens; melhor que qualquer outro, ele compreendeu que a fantasmagoria do sonho escondia mais ainda do que mostrava, e que o sonho não era senão um compromisso inteiramente habitado de contradições. Mas, de fato, o compromisso não é entre o recalcado e a censura, entre as pulsões instintivas e o material perceptivo; ele está entre o movimento autêntico do imaginário e sua adulteração na imagem. (Foucault, 1954/1999, p. 119)

O ponto cego do sonho reside no fato das imagens, enquanto representantes de objetos reais oriundas do mundo diurno, estabelecerem uma passagem descontínua. "A imagem não é mais imagem de alguma coisa" (Foucault, 1954/1999, p. 120), mas a ausência que permite a consideração sobre uma obra de arte, sui generis. Estética da linguagem colocada como apreciação e invenção. A criação que ulula por entre caminhos tortuosos e sem destino, excedentes da imagem institucionalizada, da imagem que cremos ser a única com todas as forças.

Dito isto, perguntamos: para onde se encaminha nossa expressão criativa? Qual é a vida que a percepção por vezes prefere obscurecer, mas sustenta na escolha do que é simplificado pela representação? Sustentar a liberdade não é tão simples como parece. Significa sustentar toda a ética na qual inclusive o sentido sensível irá se rebelar diante das fórmulas do enclausuramento que o determinam.

\section{A vida como obra de arte}

O que ainda deve ser analisado por nós para além das classificações e juízos valorativos? Uma psicanálise que possa ser pensada a partir de um ponto da autoria sem a necessidade de corresponder à pressa da fala irá revelar uma escrita. A conferência $O$ que é um autor? de 1969, pronunciada na Sociedade Francesa de Filosofia, expõe esta proposição: "Na escrita, não se trata da manifestação ou da exaltação do gesto de escrever, nem da fixação de um sujeito numa linguagem; é uma questão de abertura de um espaço onde o sujeito de escrita está sempre a desaparecer.” (Foucault, 1969/1992, p. 35). Desaparecer é uma força capaz de silenciar outros sentidos insubmissos ao texto, mas bem adaptados a uma das maiores de todas as operações modernas: matar o autor.

Quem é o que escreve? Talvez quando começamos a perguntar por "quem é” já estejamos criando uma pergunta muito difícil de responder. Talvez devêssemos começar por outra maneira de perguntar, como, por exemplo, acerca do que já foi criado, da criação propriamente dita. É neste ponto que a discussão nos leva a um ponto, no passado de algumas figuras, e entre a querela obra e autor. Dizer que autor viveu de determinada forma e que isso comprova certos traços de sua obra é fazer uso de uma técnica moderna de leitura. Este esquema reduz o texto à figura do autor, o que claramente causa um peso no sentido da obra. O peso da interpretação recai em um conjunto de assuntos que não foram devidamente abordados no final do século de XIX por Nietzsche, por exemplo. "Trata-se, sim, de localizar o espaço deixado vazio pelo desaparecimento do 
autor" (Foucault, 1992, p. 41) Quantas obras ao longo da humanidade foram escritas sem sabermos quem as realizou? E no entanto havia diferentes interpretações, níveis que eram lidos e momentos em que certas atribuições de sentido eram necessárias para que se chegasse a um tipo de entendimento estético. Estas interpretações costumam alongar a obra, esclarecendo-a ou tornando-a complexa. É a história que apanha a obra, conferindolhe um significado, portanto, um sentido em decorrência do tempo. Um discurso que se desprende da subjetividade e adquire nova significação (Ketzer, 2016) e em nosso tempo contemporâneo torna-se o status de propriedade privada (Foucault, 1969/1992). Esta maneira de sujeitar o autor a um determinado discurso apropriativo constrói valores a serem repetidos à exaustão para dali retirar um benefício, um manual para ler a obra, por exemplo. “Noutros termos, para 'reencontrar' o autor na obra, a crítica moderna utiliza esquemas muito próximos da exegese cristã quando esta queria provar o valor de um texto através da santidade do autor." (Foucault, 1992, p. 51) Atribuir um sentido que seja anterior à obra, mais arcaico e mais legítimo, também é um certo desprezo à obra e sua gramática interna, leia-se: “a lei de composição interna da obra”. Assim, aceita-se o que parece mais cômodo a um determinado sentido, mesmo que seja através de disciplinas não estéticas, tais como a história e a psicologia.

Na conferência $A$ ordem do discurso, de 1970, o fator obra/autor se apresenta mais claramente: "O autor é aquele que dá à inquietante linguagem da ficção suas unidades, seus nós de coerência, sua inserção no real” (Foucault, 2006, p. 28) O autor existiu, certamente, mas as disciplinas tem o dever de colocar em dúvida a obra, formularem de modo inquietante o autor, inventar um novo jogo entre os discursos para que seu papel não recaia em uma verdade parasitária. Uma hermenêutica prima pelo descenso, mas precisa fazê-lo de forma a que seus intérpretes não maculem o conhecimento com práticas abusivas ou inacessíveis, fato este que por vezes as instituições caem ao elegerem um determinado "cânone" de leitura em detrimento de outro.

Discutir uma prática discursiva exige começar a praticar uma ética do texto de forma a eximir categorias, proporcionando o livre pensar, e o que aparentemente a discursividade teve de reconstituir enquanto sua própria história de similitudes com um objetivo representacional muito evidente. A facilitação no percurso da modernidade. Por este motivo, Foucault havia desenvolvido sua Arqueologia do saber, deixando uma alta dose de questionamentos, inclusive sobre sua atitude pessoal diante da pesquisa histórica:

Vários, como eu sem dúvida, escrevem para não ter mais um rosto. Não me pergunte quem sou eu e não me diga para permanecer o mesmo: é uma moral de estado civil; ela rege nossos papéis. Que ela nos deixe livres quando se trata de escrever. (Foucault, 1969/1995, p. 20)

Não só não ter um rosto, mas talvez o exagero causado por uma regularidade que cada vez mais soa estranha aos olhos de novas formas de experiências individuais. Um mesmo rosto numa mesma alteridade. Foucault, ao fim e ao cabo, não compactua com um território de certezas e pontos finais com qualquer postulado de verdade teleológica ou simplificada para agradar uma massa à espera de felicidade plena. $\mathrm{O}$ pensamento não deve se contentar com uma posição assim, mas é dever dos intelectuais e pensadores da cultura provocar um atrito neste regime de submissão nas diversas instituições em que estão engajados na sociedade. Os saberes deixam suas marcas e cabe a nós adentrarmos em seus diferentes estratos. 
Mais radical ainda é olhar para o futuro e para o desenvolvimento do olhar foucaultiano em direção a uma abordagem inteiramente renovada acerca da experiência humana do "si mesmo". Os processos inconscientes, onde estão? Enquanto prática cotidiana, estão em todas as partes, inclusive naquelas que ainda carecem de percepção. Dar uma mostra desse resultado é algo que teremos de fazer, doa a quem doer. Voltar à crítica dirigida à psicanálise, mas agora em um pulo de 22 anos para frente na sequência da História da Sexualidade. A criticidade sempre esteve nos trabalhos do autor, mas por outra via, mais transgressora do que a via proposta pela psicanálise. Foucault tem em mira algo que a psicanálise teria de lidar, mas em favor de um movimento mais social do que psicológico propriamente dito. Por mais que saibamos que o propriamente psicológico é antagonista do psicanalítico, quando pensamos em muitos termos encontrados na psicanálise sabemos que Freud teve de passar da neurologia para a psiquiatria, tendo forte relação com as afasias no Projeto para uma psicologia científica (Freud, 1895/1975). Freud teve até mesmo algo como uma teoria da psicossexualidade infantil vista nos Três ensaios sobre a teoria da sexualidade (Freud, 1905/1975c $)^{5}$. Sob este último diagnóstico apresentado por ele, torna-se claro um mal estar com a figura da psicanálise dentro das ciências médicas e humanas do século XIX. É importante notar que Foucault enxerga uma equiparação entre o termo "sexo" enquanto performance e a ideia de uma "sexualidade" tal como pensada pela psicanálise.

Mas, eis que a psicanálise, que parecia, em suas modalidades técnicas, colocar a confissão da sexualidade fora da soberania familiar, reencontrava, no próprio seio dessa sexualidade, como princípio de sua formação e chave de sua inteligibilidade, a lei da aliança, os jogos mesclados dos esponsais e do parentesco, o incesto. (Foucault, 1976/2003, p. 106)

Não apenas incesto, mas uma regra para a formação da subjetividade. Regra que não poderia ser quebrada, uma vez que Foucault lê as palavras freudianas como uma saturação do desejo com vista à frustração. A mãe torna-se um objeto enquanto o pai um soberano. O lugar do filho esbarra na submissão, outra questão que deixa Foucault inquieto, uma vez que o filho ocupa um lugar que assume a culpa, por isso a "exigência da confissão". (Foucault, 1976/2003, p. 123) Não por nada, o psicanalista que Foucault admira é Wilhem Reich, contestador da ordem social e muito atento à revolução sexual instaurada na década de 1930 .

Vejamos mais a fundo a crítica pelo viés da ideia de uma lei universal como princípio básico para a sexualidade, uma vez que a sexualidade se alia de algum jeito às relações familiares. Instaura-se a fantasia incestuosa como princípio:

A garantia de que lá, no fundo da sexualidade de cada um, ia-se encontrar a relação pais-filhos permitida, no momento em que tudo parecia indicar o processo inverso, manter a fixação do dispositivo de sexualidade sobre o sistema da aliança. Não havia riscos de que a sexualidade aparecesse, por natureza, estranha à lei: ela só se constituía pela lei. Pais, não receeis levar vossos filhos à análise: ela lhes ensinará que, de toda maneira é a vós que eles amam. Filhos, não vos queixeis demais de não serdes órfãos e de sempre encontrardes no fundo de vós mesmos, vossa Mãe-Objeto ou o signo soberano do Pai: é através deles que tendes acesso ao desejo. (Foucault, 1976/2003, p. 106) 
O bom filho é o ideal do bom moço na sociedade: obedece tão bem que acaba se frustrando para assim não ter de lidar realmente com o seu desejo. O desejo mesmo é ele independente dos outros ao seu redor? Vontade de potência em estado latente? E as expectativas que temos, quando representadas pelo sintoma, não seriam fruto da culpa galgada de nossos pais sobre nós mesmos? Como interromper este fluxo de expectativas? Ou melhor: será que a psicanálise teria a melhor resposta para esta questão? São algumas das dúvidas que o filósofo propõe afim de mostrar como alguns dogmas acabam sendo criados quando a força da argumentação impõe o pensamento até um substrato que não se permite mais interrogar a circunstância do método presente nos parâmetros disciplinares. Mesmo a psicanálise, a mais profunda das disciplinas que examinam a psique, ela mesma criou um método que pode institucionalizar-se muito rapidamente. O maior prejudicado é aquele que pensa, pois está à mercê da palavra do outro:

Da direção espiritual à psicanálise, os dispositivos de aliança e de sexualidade, girando um em torno do outro, de acordo com um lento processo que tem hoje mais de três séculos, inverteram suas posições; na pastoral cristã, a lei da aliança codificava essa carne que se estava começando a descobrir e impunhalhe, antes de mais nada, uma armação ainda jurídica; com a psicanálise, é a sexualidade que dá corpo e vida às regras da aliança, saturando-as de desejo. (Foucault, 1976/2003, p. 107)

Foucault vê na elaboração teórica do Édipo a perda jurídica do poder paterno, tal como o fato de, entre 1889 e 1898, ser criada uma lei na França que torna crime ter um amante. A organização do recalque num discurso, o desejo incestuoso, para entender as origens míticas do incesto, é algo que vem ao encontro de necessidades sociais, por mais que isso seja contra cultural para a Viena do final do século XIX. "Os que tinham perdido o privilégio exclusivo de se preocupar com sua própria sexualidade tem, doravante, o privilégio de experimentar mais do que outros o que a interdita, e possuir o método que permite eliminar o recalque.” (Foucault, 1976/2003, p. 122). Para Foucault a psicanálise revela o escondido, mas o faz para reativar os mecanismos de repressão que justamente estão sobrepostos. Como o tempo vivido e o ambiente acabam dando às ideias um determinado realce que anteriormente não estávamos atentos, Foucault logo se posiciona em defesa das coisas antes da determinação em palavras: seguir o descompasso do pensamento diante do mundo sem o julgamento e o excesso de pessoalidade que faz a redução e gera o mal entendido. O que se pode entender de um discurso quando a fala não é simples inteligibilidade binária do "é” ou do "não é” verdade? Não está escrito que há facilitações, ainda que a crítica de Foucault acabe sendo sobre o modo estruturalista do estruturalismo fracionar a realidade em exterioridades sem fim, Foucault também não o faria em dado sentido, por um esquema de equivalência temporal, chamado de análise sincrônica? ${ }^{6}$

O filósofo também cai em um lugar que impreterivelmente fala do exterior. Sua inteligência teve de observar os outros movimentos da psicanálise na França, tal como será acerca do movimento lacaniano, pois a instância do eu (je), também ela é fracionada e em busca de uma liberdade pouco vislumbrada em sua época. Lacan tem uma importância evidente: "Ele queria que o leitor se descobrisse, ele próprio, como sujeito do desejo, através dessa leitura.” (Foucault, 1999, p. 299). Esta entrevista de Foucault é interessante para um entendimento da psicanálise em sua obra. Se por um lado ele enxerga em Freud o problema do signo, em Lacan ele se refere ao desejo de uma maneira pautada na liberdade 
da interpretação. Não é menor a importância de Foucault à obra $O$ Banquete, de Platão. Se lermos atentamente suas considerações presentes em História da Sexualidade, Vol. 2, veremos o quanto ele se aproxima da interpretação lacaniana presente no Seminário, Livro 8 (Lacan, 1991/2010), de maneira a aproximar a verdade do sujeito à verdade do desejo: "Platão resolve a dificuldade do objeto do prazer reportando a questão do indivíduo amado para a natureza do próprio amor; estruturando a relação de amor como uma relação com a verdade." (Foucault, 1957/2009, p. 212) A verdade de seu próprio desejo, o que para Lacan passa pela transferência, a relação entre analista e o analisado. Contudo, para Foucault esta verdade é uma composição que está em dependência do ideal espiritual da afrodisia como prática espiritual seguida pelas classes dominantes gregas (Foucault, 1984/2009a, 1984/2009b).

Não nos adentraremos na questão da afrodisia, ainda que ela corrobore a ideia da vida como obra de arte. Neste caso, a formação do homem não possui um telos dado pelas disciplinas fundadas no século XVIII, mas está em profunda relação com o reexame e com a pergunta que cada sujeito deve fazer diante do oráculo de Delfos, pergunta essa pessoal e intransferível. O homem grego se pergunta porque precisa "cuidar de si" (epimeleia heautou), isto é, o cidadão realiza uma ética: "Não somos capazes de conhecer a verdadeira origem do desejo, a não ser através de procedimento hermenêutico" (Dreyfus \& Rabinow, 1995, p. 269) Um procedimento que não raras vezes nos faz cair em engano, portanto, nos leva a uma verdade que excede a privacidade do solilóquio, sendo assim, discursada em praça pública. Ali, a briga será entre as diferentes verdades e sobre a exigência de ouvir as verdades dos outros. Verdade tumultuada como se dá na própria psicanálise.

\section{Conclusão}

Tentamos neste trabalho aproximar como Foucault lê a psicanálise a partir das principais articulações que o pensador estabeleceu com esta disciplina. Seus duros ataques parecem muito mais galgados no modo que Foucault observou uma determinada psicanálise tomada ao pé da letra, sem levar em consideração a postura prática dos analistas, tão pouco as diferentes escolas de psicanálise que foram desenvolvidas no século $\mathrm{XX}$ - fato este que não deixa de ser uma perspectiva entre outras para uma avaliação da psicanálise fora do campo de articulação dos psicanalistas. Quando Foucault cita Lacan é para mostrar que suas análises fogem em muito a uma naturalização psicológica, pois o psicanalista francês possui interesses filosóficos que dizem respeito a um princípio mais de acordo com o modelo estruturalista de sua época: "creio que Lacan foi o único depois de Freud a querer recentralizar a questão da psicanálise precisamente nesta questão das relações entre sujeito e verdade." (Foucault, 2006, p. 40) Esta questão colocada por Foucault reacende a chama: qual é o compromisso da psicanálise? Que espécie de verdade do sujeito é esta que ela se compromete?

A questão posta desde História da Loucura não cessa de ser colocada: o que a psicanálise disse ou deixou de dizer sobre a loucura? Ela não a expressou como problema por ser de seu interesse a representação psíquica, ainda que inconsciente, pois é defendido pelo $\mathrm{Eu}(I c h)$ como via de proteção à quebra do princípio de prazer. Para uma outra psicanálise, com outros olhares e perspectivas, o que será necessário explicar? 
Para o filósofo argelino Jacques Derrida (2001), Foucault assume uma atitude ambivalente em relação à psicanálise, pois Foucault entra em contradição, identificando a psicanálise como uma disciplina entre outras dentro da medicina.

O próprio Freud terá, de fato, a figura ambígua de um porteiro. Introduzindo a uma nova época da loucura, a nossa, aquela a partir da qual se escreve a História da loucura (o livro com este título, ele representa também o melhor guardião de uma época que se encerra com ele, a história da loucura tal como é contada pelo livro que tem esse título. (Derrida, 2001, p. 103)

Freud é um porteiro como outro qualquer, porém, que não tem a ousadia de intuir-se como libertador, porém, alguém que também fecha as portas. Acreditamos que a psicanálise pense sem método, justamente ao mostrar as formações do inconsciente na vida das pessoas. Aí percebemos o quanto a psicanálise está mais implicada com a "Desrazão" do que com a loucura enquanto fenômeno. Neste ponto, a psicanálise possui um método contrário ao empirismo da psicologia.

O pesquisador carioca Joel Birman encontra justamente este viés ao ler o projeto de Foucault, a partir de seus estudos sobre a loucura, ao que tudo indica, o ponto de maior divergência entre a psicanálise e o pensamento foucaultiano. Quantos monstros vemos a sociedade ocidental aprisionando, tornando malignos os sinais que envolvem nossa própria responsabilidade? A psicanálise ausente, exteriorizada, a qual somos eximidos de pensar, ou melhor, acreditamos pensar quando de fato não o fazemos ${ }^{7}$. E a questão do pensamento comparece mais uma vez, para que possamos fazê-lo realmente livre dos aparatos institucionais rígidos que colocam o "dito" antes do "dizer". Este perigo que ronda as instituições e que Foucault brigou por tantos anos. Por isso, para ele, a arte excede os ditos. Inclusive, a vida possui um dizer que tendemos a encapsular muito facilmente. $\mathrm{O}$ saber leva mais uma vez a um caminho de difícil acesso e por vezes a um encantamento típico da voz das sereias. Foucault lembra sem cessar acerca da potência libertária contida nas personalidades errantes do mundo ocidental moderno:

Portanto, enquanto pretensão de ser um saber sobre a loucura, a psicanálise estaria inexoravelmente inscrita na tradição crítica, que fora remodelada pela psiquiatria no século XIX, inserindo-se na tradição da filosofia do sujeito e na tradição da razão refundadas por Hegel. A loucura na tradição trágica estaria fora desse espaço, presente apenas nas tradições iconográficas (Van Gogh), literária (Strindberg), dramatúrgica (Artaud), poética (Hölderlin) e filosófica (Nietzsche), herdeiros positivados do campo da desrazão. (Birman, 2000, p. 93)

Para Birman e Derrida, este papel parte da responsabilidade sobre estes que foram julgados, aqueles que não tiveram em conta a necessidade de suas vidas e no entanto suas vidas sempre foram tomadas enquanto sintomas. Esta é a dificuldade que a arte ainda nos coloca quando estamos diante de exposições públicas que tocam e mostram a nudez ou outras expressões de liberdade. Aí vem a moral para julgar e levantar-se como último predicado da salvação. Este obstáculo ainda a ser enfrentado de classificar a loucura pela patologia, este julgamento que se antecede como tentativa de explicação rasteira. Aqui também psicanalistas têm muito a aprender. 


\section{Notas}

1 Não é nossa intenção nos alongarmos demais pela via conceitual. Entretanto, se faz necessário atentar acerca de como Agamben (2009, p. 38) compreende tal categoria: "O termo dispositivo nomeia aquilo em que e por meio do qual se realiza uma pura atividade de governo se, nenhum fundamento no ser. Por isso os dispositivos devem sempre implicar um processo de subjetivação, isto é, devem produzir o seu sujeito.” Voltaremos ao termo para esmiuçar tudo o que escapa aos "universais", ou seja, as instituições que regulam a vida social humana de maneira abstrata. O Estado é uma delas.

2 Este trabalho foi recentemente traduzido para o português por Marco Antonio Casanova, intitulado Sonho e Existência (Binswanger, 2013).

3 Por este motivo, vemos o trabalho de Jürgen Habermas (1985/2002) em $O$ discurso filosófico da Modernidade dar exemplos de tantos autores, inclusive ele mesmo, explorando os achados da psicanálise a partir de um ponto de vista hermenêutico profundo. Este fato que ocasionou uma mudança na postura da filosofia que terá de se posicionar não apenas diante das ciências exatas, mas também entrar no debate entre a contextualidade e o semanticismo que reverberam na psicanálise. A posição de Habermas leva em conta os conceitos elaborados internamente pelo conhecimento psicanalítico e os introduz em seu sistema da teoria da ação comunicativa. Esta escolha corrobora a teoria da ação comunicativa como em dependência das decisões semânticas do analista em detrimento do paciente (Navia, 1999).

4. De uma perspectiva absolutamente diferente de Jung, encontramos na psicanálise pós-freudiana o termo revêrie, em alusão direta ao trabalho de Melanie Klein e Wilfred R. Bion. Em tradução, o termo significa "devaneio", mas está intimamente ligado desenvolvimento da capacidade de pensar, saindo da projeção (o conteúdo da pulsão de morte), para uma instância criativa, aumento da capacidade do inconsciente, nível simbólico da linguagem. Foucault é inspirado pela ideia de imaginário com a perspectiva de se professor Gaston Bachelard (1960/2009), vemos o quanto ela se aproxima de D. W. Winnicott (1975), por exemplo, quando o autor inglês desenvolve a ideia de "objeto transicional".

O termo "sexualidade" deve ser entendido como satisfação das zonas erógenas.

6 Ainda que o filósofo utilize a história como ponto de partida para suas operações, temos de vislumbrar o quanto essa dita história (diacronia) segue o exemplo de uma sequência de questionamentos postos por Foucault no tempo presente e, portanto, sincrônico a partir de onde seu pensamento começa a esboçar a discussão entre os saberes da modernidade.

7 Pensar aqui faz referência ao trabalho de Bion Uma teoria sobre o pensar, de 1962, o qual está em dependência do desenvolvimento de outros aparelhos para lidarmos com as frustrações e com os limites, isto é, um elemento de simbolização (Bion, 1967/1994). 


\section{Referências}

Agamben, G. (2009). O que é o Contemporâneo? E outros ensaios. Chapecó, SC: Argos. Bachelard, G. (2009). A poética do devaneio. São Paulo: Martins Fontes. (Original publicado em 1960)

Binswanger, L. (2013). Sonho e Existência: ensaios e conferências 1: escritos sobre fenomenologia e psicanálise. Rio de Janeiro: Via Verita.

Bion, W. R. (1994). Uma teoria sobre o pensar. In Estudos psicanalíticos revisados - Second Thoghts (pp. 127-138). Rio de Janeiro: Imago. (Original publicado em 1967)

Birman, J. (2000). Entre Cuidado e Saber de si: sobre Foucault e a psicanálise. Rio de Janeiro: Relume Dumará.

Derrida, J. (2001). Fazer justiça à Freud: a história da loucura na era da psicanálise. In J. Derrida \& M. Foucault (Orgs.), Três tempos sobre a história da loucura (pp. 92-151). Rio de Janeiro: Relume Dumará. (Original publicado em 1992)

Dreyfus, H. L. \& Rabinow, P. (1995). Michel Foucault: uma trajetória filosófica para além do estruturalismo e da hermenêutica. Rio de Janeiro: Forense Universitária.

Foucault, M. (1977). O nascimento da clínica. Rio de Janeiro: Forense Universitária.

Foucault, M. (1987). Vigiar e punir: nascimento da prisão. Petrópolis, RJ: Vozes. (original publicado em 1975)

Foucault, M. (1992). O que é um autor? Lisboa: Passagens. (Original publicado em 1969)

Foucault, M. (1995). A arqueologia do saber. Rio de Janeiro: Forense Universitária. (Original publicado em 1969)

Foucault, M. (1999a). A psicologia de 1850 a 1950. In Ditos e Escritos, vol 1 - Problematização do sujeito: Psicologia, Psiquiatria e Psicanálise (pp. 122-153). Rio de Janeiro: Forense Universitária. (Original publicado em 1957)

Foucault, M. (1999b). Introdução (in Binswanger). In Ditos e escritos, vol 1 - Problematização do sujeito: psicologia, psiquiatria e psicanálise. Rio de Janeiro: Forense Universitária. (Original publicado em 1954)

Foucault, M. (1999c). Lacan, o "Libertador" da Psicanálise. In Ditos e escritos, vol 1 - Problematização do sujeito: psicologia, psiquiatria e psicanálise (pp. 298-299). Rio de Janeiro: Forense Universitária. (Original publicado em 1981)

Foucault, M. (2003). História da sexualidade, vol. 1: a vontade de saber. Rio de Janeiro: Edições Graal. (Original publicado em 1976)

Foucault, M. (2004). História da loucura. São Paulo: Perspectiva. (Original publicado em 1961)

Foucault, M. (2005). Um diálogo sobre os prazeres do sexo - Nietzsche, Freud e Marx - Theatrum Philosoficum. São Paulo: Landy Editora. (Original publicado em 1982)

Foucault, M. (2006). A ordem do discurso. São Paulo: Edições Loyola. (Original publicado em 1970)

Foucault, M. (2006). A Hermenêutica do Sujeito: Curso dado no College de France (19811982). (M. A. Fonseca \& S. T. Muchail, trads.) São Paulo: Martins Fontes.

Foucault, M. (2007). As palavras e as coisas. São Paulo: Martins Fontes. (Original publicado em 1966)

Foucault, M. (2009a). História da sexualidade, vol. 2: o uso dos prazeres. Rio de Janeiro: Graal. (Original publicado em 1984)

Foucault, M. (2009b). História da sexualidade, vol. 3: o cuidado de si. Rio de Janeiro: Graal. (Original publicado em 1984)

Foucault, M. (2013). Microfísica do poder. São Paulo: Graal. (Original publicado em 1979) 
Freud, S. (1975a). Projeto para uma psicologia científica. In Obras psicológicas completas brasileiras de Sigmund Freud (J. Salomão, trad., pp. 303-420). Rio de Janeiro: Imago. (Original publicado em 1950 [1895])

Freud, S. (1975b). A interpretação dos sonhos. In Obras psicológicas completas brasileiras de Sigmund Freud (J. Salomão, trad., pp. 17-634). Rio de Janeiro: Imago, Vol. IV e V. (Original publicado em 1900)

Freud, S. (1975c). Três ensaios sobre a teoria da sexualidade. In Obras psicológicas completas brasileiras de Sigmund Freud (J. Salomão, trad., pp. 123-252). Rio de Janeiro: Imago, Vol. VII. (Original publicado em 1905)

Habermas, J. (2002). O discurso filosófico da modernidade. São Paulo: Martins Fontes. (Original publicado em 1985)

Ketzer, E. N. (2016). Asserção breve sobre o discurso na obra de Michel Foucault: do moderno ao antigo. In N. R. Madarasz, G. M. Jaquet, D. N. Fávero, \& N. Centenaro (Orgs.), Foucault: leituras acontecimentais ( $1^{\mathrm{a}}$ ed., pp. 375-400). Porto Alegre: Editora Fi. Recuperado de https:// www.editorafi.org/053norman

Lacan, J. (2010). Seminário, Livro 8: a transferência (1960-1961). Rio de Janeiro: Jorge Zahar. Navia, R. (1999). Principais críticas da filosofia contemporânea da ciência à psicanálise: esboço de respostas. In J. A. T. Machado (Org.). Filosofia e Psicanálise: um diálogo (pp. 159183). Porto Alegre: EDPUCRS.

Ricoeur, P. (1978). O conflito das interpretações: ensaios de hermenêutica. Rio de Janeiro: Imago.

Wimmicott, D. W. (1975). O brincar e a realidade. Rio de Janeiro: Imago.

\section{ESTEVAN KETZER}

https://orcid.org/0000-0003-4419-9333

Psicólogo. Doutor em Letras (PUCRS).

Endereço: Rua Dona Laura, 228, sala501, MoinhosdeVento, Porto Alegre/

RS, CEP 90430090. https://estevanketzer.wixsite.com/estevanketzer

E-mail: estevanketzer@gmail.com

\begin{tabular}{|l|l|}
\hline Histórico & $\begin{array}{l}\text { Submissão: 01/08/2018 } \\
\text { Revisão: 05/04/2020 } \\
\text { Aceite: 12/06/2020 }\end{array}$ \\
\hline Contribuição dos autores & Não se aplica. \\
\hline Consentimento de uso de imagem & Não se aplica. \\
\hline Aprovação, ética e consentimento & Não se aplica. \\
\hline Financiamento & Não houve. \\
\hline
\end{tabular}

